\title{
Cataract surgery: factors influencing decision to treat and implications for training (south-east Scotland 2008-2014)
}

This article was published in the following Dove Press journal:

Clinical Ophthalmology

28 September 2015

Number of times this article has been viewed

\author{
Jan J Sniatecki \\ Caroline Styles \\ Natalie Boyle \\ Roshini Sanders
}

Cataract Unit, Queen Margaret Hospital, Dunfermline, Fife, UK

Correspondence: Roshini Sanders; Jan J Sniatecki

Cataract Unit, Queen Margaret Hospital, Whitefield Road, Dunfermline, KYI2 OSU, Fife, UK

Tel +44 I383623623

Email roshini.sanders@nhs.net; jan.sniatecki@gmail.com
Purpose: To describe the population referred for cataract surgery, identify factors that influenced decision to treat, and patients suitable for ophthalmic training.

Patients and methods: A total of 2,693 consecutive referrals over 6 years were interrogated using Business Objects software on cataract electronic patient records.

Results: A total of 2,693 patients were referred for cataract surgery (group A). Of these patients 2,132 (79\%) had surgery (group B) and 561 (21\%) did not (group C). Age for group B vs group C: $672(32 \%)$ vs $115(20 \%) \leq 69$ years, $P<0.001 ; 803$ (38\%) vs $225(40 \%) 70-79$ years, $P=0.48$; $586(27 \%)$ vs 203 (36\%) 80-89 years, $P<0.05 ; 71$ (3\%) vs $18(3 \%) \geq 90$ years, $P=1.0$. Visual acuity, group B vs group C: 556 (26\%) vs 664 (59\%) 6/12 or better; 1,275 (60\%) vs 367 (33\%) $6 / 18-6 / 60 ; 266(12 \%)$ vs 64 (6\%) counting fingers or worse, $P<0.05$. Medical history for group B vs C: cognitive impairment: 55 (2.6\%) vs 29 (5.2\%), $P<0.05$; cardiovascular accident: 158 (7.4\%) vs 60 (10.7\%), $P<0.05$; diabetes: 372 (17.4\%) vs 96 (17.1\%), $P=0.87$; COPD/asthma: 382 (17.9\%) vs 93 (16.6\%), $P=0.53$; heart disease: 535 (25.1\%) vs 155 (27.6\%), $P=0.35$; hypertension: 971 (45.5\%) vs 263 (46.9\%), $P=0.73$. Ocular history for group $\mathrm{B}$ vs $\mathrm{C}$ was significant $(P<0.05)$ for age-related macular degeneration $255(12.0 \%)$ vs $93(16.6 \%)$, other macular pathology $38(1.8 \%)$ vs 25 (4.5\%), corneal pathology 92 (4.3\%) vs $36(6.4 \%)$, amblyopia $37(1.7 \%)$ vs $22(3.9 \%)$. Detailed data on presenting complaint, ophthalmic history, and social status is discussed.

Conclusion: We observed that surgery at a younger age with good levels of visual acuity was a factor in deferring cataract surgery. Cognitive impairment, cardiovascular accident, amblyopia, corneal and macular pathology significantly affected decision not to operate. We estimate that $80 \%$ of patients would be suitable for ophthalmic training.

Keywords: audit, electronic patient record, cataract surgery, co-morbidity, guarded visual prognosis, ophthalmic training

\section{Introduction}

Cataract is an important cause of visual impairment world-wide and cataract surgery is the commonest elective surgical intervention in the UK and developed world. It is predicted that a quarter of the population of the UK will develop cataracts by the age of 75 years. In Scotland, 33,064 cataract extractions were performed in the year $2010 / 2011$ compared to 20,578 in the year 2001/2002 with an increasing trend year upon year, despite a stable population. As at June 2013, 4,088 people were on the waiting list for outpatient assessment for cataract surgery in National Health Service (NHS), Scotland. This number has nearly doubled over the previous year since June 2012 when only 2,403 people were reported to be waiting for cataract assessment. ${ }^{1-4}$

These numbers reflect the tremendous increased demand for cataract surgery, the causes of which are multifactorial and include an ageing population, better access 
to treatment, faster surgical technique and rehabilitation, increased education, and public awareness of the benefits of cataract surgery. This has reached a point where the possibility of over-provision of cataract surgery in some regions has been described in the literature. ${ }^{5}$

Currently, there are no specific thresholds or criteria that define appropriate patients for referral and/or cataract surgery. Referral methods and pathways to surgery vary greatly throughout the UK depending on locally agreed protocols. The most up-to-date Royal College of Ophthalmologists Cataract Surgery Guidelines from September 2010 give no specific visual acuity threshold for surgery. ${ }^{6}$ However, the guidelines highlight the importance of cataract impact on patient lifestyle, balancing the risks and benefits of surgery when taking a decision to perform the operation. Other factors to consider are patients' ocular and non-ocular co-morbidities, as well as the effect of first and second eye cataract surgery. Some effort has been made to produce questionnaires evaluating the impact of cataract on quality of life issues. However they often lack applicability to certain patient groups and have not found routine use in the NHS.

Some studies show that optometric cataract referrals provide better information on objectively measured vision and better delivery of patient preoperative counselling, whereas traditional GP referrals contain better medical history, drug information, and details of personal circumstances. ${ }^{7}$ There is no single test to assess the effect of cataracts on a patient nor is there a test to decide on threshold for surgery. This results in a wide range in the type of patient referred for cataract surgery, from those with very minimal disability to those with severe visual impairment.

Moreover, the literature shows that visual impairment is very often associated with multiple physical and mental health co-morbidities that need to be taken into account by both patient and surgeon when a patient is being considered for cataract surgery. ${ }^{8}$ It has also been suggested that the significant variation in cataract surgery rates across the UK is caused by differences in cataract referral patterns. ${ }^{9}$

With the increased rate of cataract surgery it would be expected that opportunities for training would be increased. In reality, there have been recent concerns on the wide variation in training opportunities. In particular specifically about the number of cataract operations performed by trainees as well as the range and mix of cases and the ability to deal with intraoperative complications. In some regions the failure to cope with the increased demand has resulted in straightforward cases being sourced out to external providers. This has resulted in an imbalance in the type of cases being treated within the NHS and consequently difficulty in identifying cases suitable for training. ${ }^{10-12}$

The Queen Margaret Hospital in Fife serves a population of 400,000 and carries out all cataract surgeries for the region. In 2000 a state of the art purpose built cataract unit was built consequent upon Action on Cataracts. Good Practice Guidance being published by the Royal College of Ophthalmologists. ${ }^{13}$ The new unit embraced all the steps required for efficient cataract assessment and treatment to include detailed optometrist referral information before a one stop cataract clinic (OSCC) hospital assessment and surgery. Patients were only booked into this service with an optometry referral, which provided crucial information on best corrected visual acuity (BCVA) with updated refraction data and details on other ophthalmic diseases. Simultaneously, the patient's general practitioner provided details on medical and drug history, and social circumstances. At the OSCC all patients had their medical history collated and entered into a cataract electronic patient record (CEPR) by specialist cataract nurses. Following this, patients were examined by consultants at the same appointment, with entry of all clinical examination data into CEPR. In 2004 the Fife unit published on redesign and modernization of cataract surgery services and was quoted by the Royal College of Ophthalmologists as an example of best current practice and a leader in cataract surgery provision. ${ }^{10}$ However in the last 5 years significant discrepancies between referral patterns, demand, capacity, and ability to continue training began to emerge, thus resulting in the current study.

The purpose of this observational, retrospective study was to identify main factors that influenced referral for cataract surgery and investigate the electronic patient record dataset from years 2008 to 2014 on patient demographics, co-morbidities, and cataract surgery trends. In particular, we wanted to investigate and compare the patient population that did and did not have cataract surgery in order to establish the main reasons for patients not having cataract surgery, and to evaluate the efficiency of our current cataract surgery service. A second goal was to identify patients who were or were not suitable, as the case may be, for ophthalmic training.

\section{Material and methods}

An anonymized data set of 2,693 consecutive referrals for cataract surgery to three consultants, made over a period of 6 years from 2008 to 2014, was obtained from the OSCC. The CEPR was interrogated using Business Objects software (Enterprise XI 3.1; SAP BusinessObjects, San Jose, CA, USA) for details on the following referral parameters: sex, age, BCVA, presenting complaint, past medical history, past 
ophthalmic history, prostatic and other drug history, and social circumstances. Patients who went on to have cataract surgery were identified and a more detailed study of this group particularly for ocular co-morbidities was conducted. This was in order to quantify patients who were considered suitable for training, thus allowing an estimate of training capacity. The data were transferred to and analyzed using Microsoft Office Excel (Microsoft Corporation, Redmond, WA, USA).

Patient identifiers were completely stripped out, site and clinician were anonymized. Ethics approval was not required, as this study was an audit and no patients or health workers were identifiable.

Detailed analysis was conducted for all patients who underwent cataract surgery as well as those who did not have cataract surgery. The BCVA was the best visual acuity with habitual correction or best pinhole visual acuity in the absence of correction. For patients who did not undergo cataract surgery, the best visual acuity (of either eye) was collected. Data on prostatic drug usage were collected only in years 2010-2014, as this is when the question was introduced in the CEPR.

The decision to not proceed with cataract surgery was a consultant opinion taking into account age, vision, ophthalmic examination findings, and most important of all patient expectation and opinion. This consensus decision could not be analyzed in detail as there was only limited narrative in the CEPR as to the reasons behind this decision. Thus we chose to compare all individual parameters between the two groups to come to some broad conclusions. Chi-square tests were used to determine statistical significance of difference between groups. Fisher's exact test was used for small $(<10)$, sparse, or unbalanced data. Statistical analysis was performed in Microsoft Office Excel and Stata (StataCorp LP, College Station, TX, USA).

\section{Results}

In the years 2008-2014, 2,693 consecutive referrals to three consultants were made for cataract surgery (group A). Of this group, 2,132 (79\%) went on to have cataract surgery (group B), and 561 (21\%) did not have surgery (group C). There were 1,243 (58\%) females, $889(42 \%)$ males in group B; and 368 (66\%) females, 193 (34\%) males in group C. In group B, 767 (36\%) patients lived alone and this was the same percentage for group C, 204 (36\%), $P=0.9$.

In group B, the mean age was 74 years, median 75 years, and standard deviation 10.65 years. The age distribution was: $672(32 \%) \leq 69$ years; $803(38 \%)$ between $70-79$ years; 586 $(27 \%)$ between $80-89$ years and $71(3 \%) \geq 90$ years of age.

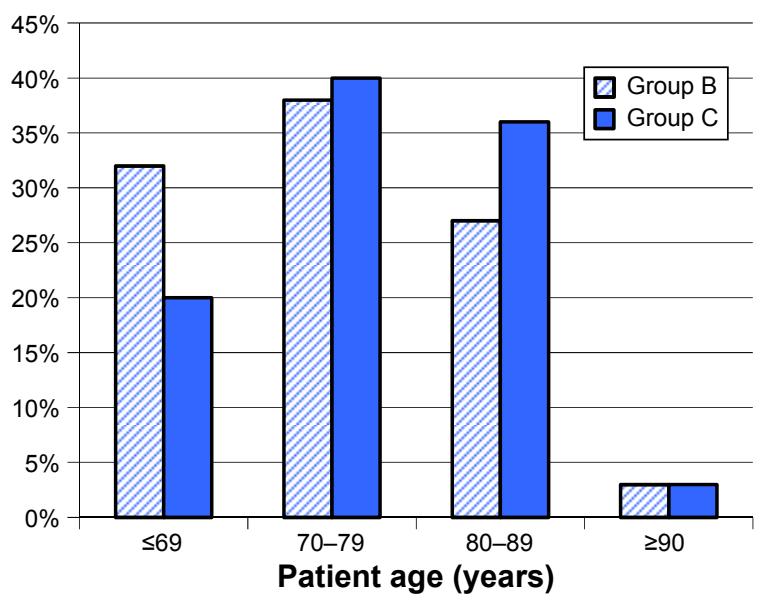

Figure I Age distribution in patients who had cataract surgery (group B) and who did not have surgery (group C).

Notes: For group B: 672 (32\%) were $\leq 69$ years; 803 (38\%) 70-79 years; 586 (27\%) $80-89$ years, 7 I $(3 \%) \geq 90$ years. For group C: $115(20 \%)$ were $\leq 69$ years, 225 (40\%) 70-79 years, $203(36 \%)$ 80-89 years and $18(3 \%) \geq 90$ years old. There was a statistically significant difference between group $B$ and $C$ in those who were 68 years and below and $80-89$ years old $(P<0.05)$.

In group C, mean age was 76 years, median 78 years, standard deviation 9.30 years. One hundred and fifteen $(20 \%)$ patients were $\leq 69$ years, 225 (40\%) 70-79 years, $203(36 \%)$ 80-89 years, and $18(3 \%) \geq 90$ years of age. The $P$-values for the following groups are: $\leq 69$ years, $P<0.001 ; 70-79$ years, $P=0.48 ; 80-89$ years, $P<0.05 ; \geq 90$ years, $P=1.0$. There was a statistically significant difference in age with more patients below 69 years in group B and more patients between $80-89$ years in group $C$ (Figure 1).

BCVA distribution at listing in the operated eye (group B) was: 556 (26\%) 6/12 or better; 1,275 (60\%) 6/18-6/60; 266 $(12 \%)$ counting fingers (CF) or worse. BCVA in group $\mathrm{C}$ for left and right eye was: 664 (59\%) 6/12 or better; 367 (33\%)

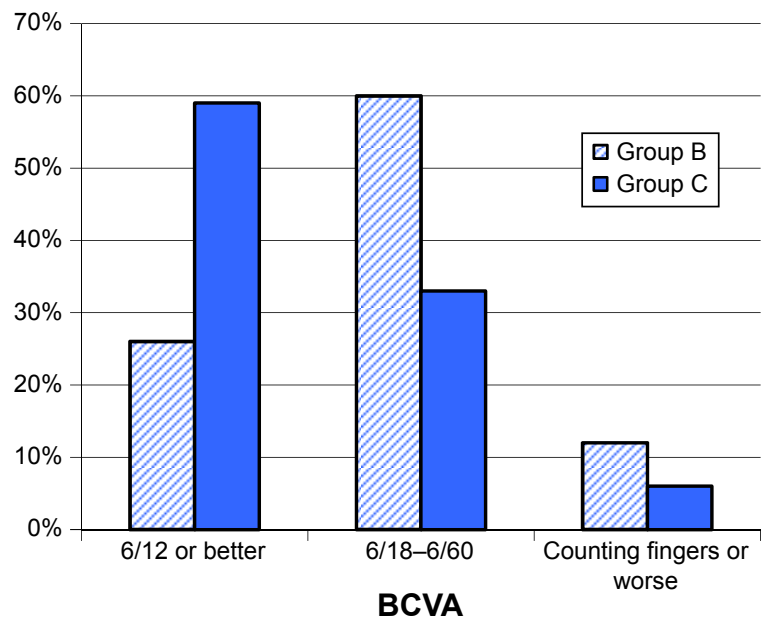

Figure 2 Best corrected visual acuity (BCVA) distribution at listing. Notes: There was a statistically significant difference $(P<0.05)$ in all groups between the operated eye (group B): 556 (26\%) 6/I2 or better; I,275 (60\%) 6/I8-6/60; 266 (I2\%) counting fingers or worse, and eyes of patients who did not have surgery (group C): 664 (59\%) 6/12 or better; 367 (33\%) 6/18-6/60; 64 (6\%) counting fingers or worse. 


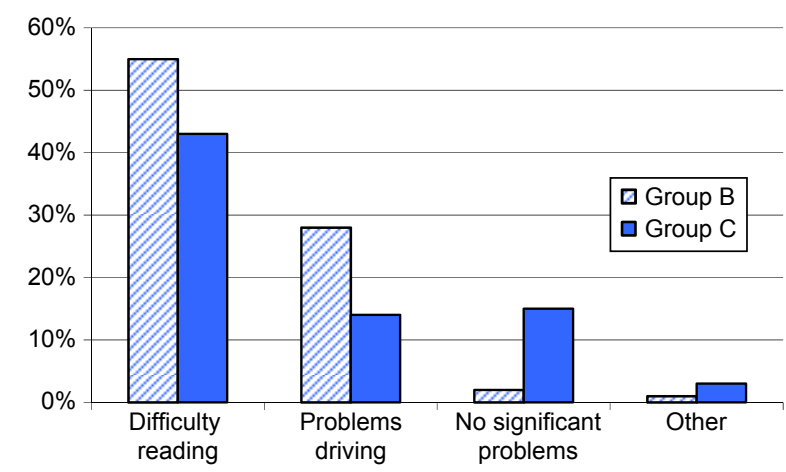

Figure 3 Presenting complaints.

Notes: The presenting complaint for the group that had cataract surgery (group B): I, I 76 (56\%) difficulty reading; 605 (28\%) problems driving; $40(2 \%)$ no significant problems; 17 ( $1 \%$ ) other problems and for those who did not have surgery (group C): 242 (43\%) difficulty reading; 8 I (14\%) problems driving; 85 (I5\%) no significant problems; $15(3 \%)$ other problems $(P<0.05)$. It should be noted that patients may have had more than one presenting complaint.

6/18-6/60; 64 (6\%) CF or worse (Figure 2). There were no clinical data available for $2 \%$ of patients in each group (group $\mathrm{B}-35$ patients, group $\mathrm{C}-13$ patients). There was a statistically significant difference with more patients having vision of $6 / 12$ or better and less patients having vision of 6/18-6/60 and CF or worse in group $\mathrm{C}(P<0.05)$.

The presenting complaint for group B was: $1,176(56 \%)$ difficulty reading; $605(28 \%)$ problems driving; $40(2 \%)$ no significant problems; 17 (1\%) other problems. For group C the presenting complaint was: 242 (43\%) difficulty reading; 81 (14\%) problems driving; 85 (15\%) no significant problems; 15 (3\%) other problems (Figure 3). There were significantly less problems with reading and driving and more patients with no visual problems in group $\mathrm{C}(P<0.05)$.

Past medical history in group B vs group $\mathrm{C}$ was for dementia/cognitive impairment (CI): 55 (2.6\%) vs $29(5.2 \%)$, $P<0.05$; cardiovascular accident (CVA): $158(7.4 \%)$ vs

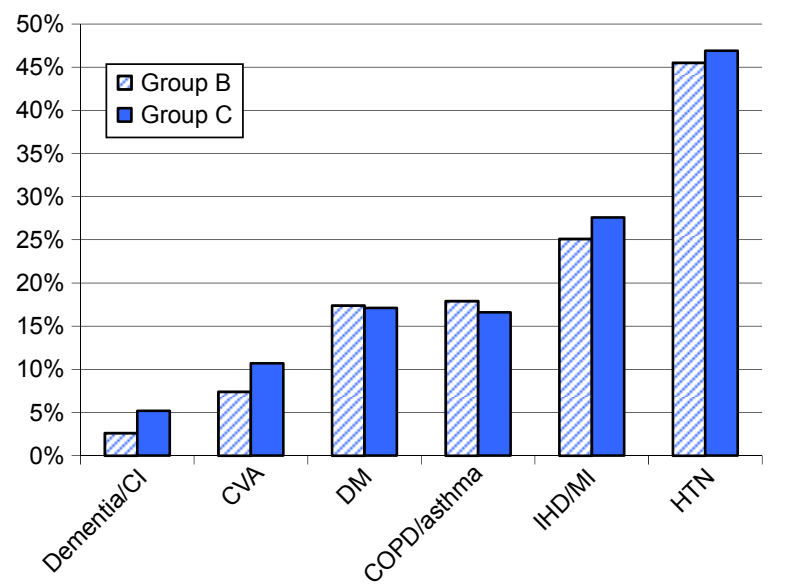

Figure 4 Past medical history.

Notes: Past medical history in group $B$ versus group $C$ for dementia/cognitive impairment $(\mathrm{Cl})$ : 55 (2.6\%) vs $29(5.2 \%), P<0.05$; cardiovascular accident (CVA): I58 (7.4\%) vs 60 (I0.7\%), $P<0.05$; diabetes mellitus (DM): 372 (I7.4\%) vs 96 (17.1\%), $P=0.87$; COPD/asthma: 382 (I7.9\%) vs 93 (16.6\%), $P=0,53$; ischemic heart disease (IHD) or myocardial infarction (MI): 535 (25.1\%) vs I55 (27.6\%), P=0.35; hypertension (HTN): 971 (45.5\%) vs 263 (46.9\%), $P=0.73$. There is a statistically significant difference between group $\mathrm{B}$ and $\mathrm{C}$ for dementia/Cl and CVA only. It should be noted that patients may have had more than one medical condition.

60 (10.7\%), $P<0.05$; diabetes mellitus: $372(17.4 \%)$ vs 96 (17.1\%), $P=0.87$; COPD/asthma: $382(17.9 \%)$ vs $93(16.6 \%)$, $P=0.53$; ischemic heart disease or myocardial infarction: 535 (25.1\%) vs 155 (27.6\%), $P=0.35$; hypertension: 971 (45.5\%) vs 263 (46.9\%), $P=0.73$ (Figure 4). There was a statistically significant difference with more patients having dementia and/or $\mathrm{CI}$ in group $\mathrm{C}$ than in group $\mathrm{B}(P<0.05)$.

For group B, 320 (15\%) had completed first eye cataract surgery and $662(31.1 \%)$ had an ocular history. In group C, 53 (9\%) had previous cataract surgery and $231(41.2 \%)$ had an ocular history. Significantly more patients in group $\mathrm{C}$ had an ocular history $(P<0.05)$. Table 1 summarizes detailed ocular history for group B and C.

Table I Ocular history in patients who had cataract surgery (group B) and who did not have surgery (group C)

\begin{tabular}{|c|c|c|c|c|c|}
\hline \multirow[t]{2}{*}{ Ocular history } & \multicolumn{2}{|l|}{ Group B } & \multicolumn{2}{|l|}{ Group C } & \multirow[t]{2}{*}{ P-value } \\
\hline & Number & Percentage & Number & Percentage & \\
\hline Nil or pseudophakia & $\mathrm{I}, 470$ & $68.9 \%$ & 330 & $58.8 \%$ & 0.04 \\
\hline ARMD & 255 & $12.0 \%$ & 93 & $16.6 \%$ & $<0.05$ \\
\hline No fundal view & 149 & $7.0 \%$ & I & $0.2 \%$ & $<0.05$ \\
\hline High myopia (-6.0 D and more) & 147 & $6.9 \%$ & 30 & $5.3 \%$ & 0.19 \\
\hline Corneal pathology & 92 & $4.3 \%$ & 36 & $6.4 \%$ & 0.04 \\
\hline Glaucoma & 65 & $3.0 \%$ & 24 & $4.3 \%$ & 0.15 \\
\hline Other macular pathology & 38 & $1.8 \%$ & 25 & $4.5 \%$ & $<0.05$ \\
\hline Amblyopia & 37 & $1.7 \%$ & 22 & $3.9 \%$ & $<0.05$ \\
\hline Diabetic retinopathy & 24 & $1.1 \%$ & 8 & $1.4 \%$ & 0.52 \\
\hline PSX & 18 & $0.8 \%$ & 1 & $0.2 \%$ & 0.24 \\
\hline Other retinal vascular pathology & 12 & $0.6 \%$ & 6 & $1.1 \%$ & 0.15 \\
\hline
\end{tabular}

Note: It should be noted that patients may have had more than one ocular co-pathology identified.

Abbreviations: ARMD, age-related macular degeneration; PSX, pseudoexfoliation syndrome. 
Table 2 Ocular co-pathology and reasons for a guarded visual prognosis for group $B$

\begin{tabular}{lll}
\hline $\begin{array}{l}\text { Ocular co-pathology/reasons } \\
\text { for a guarded visual prognosis }\end{array}$ & Number & Percentage \\
\hline Adnexa & & \\
$\quad$ Nil & 1,930 & $90.5 \%$ \\
Blepharitis/meibomianitis & 109 & $5.1 \%$ \\
Blepharospasm & 5 & $0.2 \%$ \\
Difficult access & 33 & $1.5 \%$ \\
Other & 18 & $0.8 \%$ \\
Squint & 7 & $0.3 \%$ \\
Cornea & & \\
Nil & 1,872 & $87.8 \%$ \\
Scarring & 24 & $1.1 \%$ \\
Endothelial dystrophy/changes & 29 & $1.4 \%$ \\
Guttata & 18 & $0.8 \%$ \\
Other & 21 & $1.0 \%$ \\
Anterior chamber & & \\
Deep and quiet & 2,055 & $96.4 \%$ \\
AC $<2.5$ mm & 5 & $0.2 \%$ \\
Pupil $<4$ mm & 9 & $0.4 \%$ \\
PSX & 18 & $0.8 \%$ \\
PS & 4 & $0.2 \%$ \\
\hline N & &
\end{tabular}

Note: It should be noted that patients may have had more than one ocular copathology identified.

Abbreviations: AC, anterior chamber; PSX, pseudoexfoliation syndrome; PS, posterior synechia.

Statistically significant differences were calculated for age-related macular degeneration, corneal pathology, other macular pathology and amblyopia $(P<0.05)$ - all these conditions were greater in group $\mathrm{C}$.

The findings of adnexal, corneal and anterior chamber co-pathology have been quantified for group B only and are shown in Table 2. Between 2010-2014 117 (8\%) patients were on prostatic drugs in group B.

\section{Discussion}

Our study shows relevant findings with regard to referral of patients for cataract surgery, factors influencing decision to perform surgery, and training capacity that will help refine and plan future services. The most striking finding was that $21 \%$ of patients were not listed despite having had prior detailed primary care optometry assessment. Each patient underwent a potentially unnecessary hospital appointment taking 2-4 hours, which is a significant waste of resources and time in the OSCC and NHS. Having analyzed all parameters between those who received (group B) and those who did not receive (group C) cataract surgery, one of the most significant findings was surgery at a younger age ( $32 \%$ aged $\leq 69$ years in group B vs $20 \%$ in group C) and more patients between the ages of $80-89$ years ( $27 \%$ vs $36 \%$ ) not having surgery. A large proportion of patients with good visual acuity of $6 / 12$ or better did not have cataract surgery ( $26 \%$ in group B vs $59 \%$ in group C). It is well known that old age is associated with a higher risk of postoperative complications such as endophthalmitis and this could be one of the reasons to not perform cataract surgery if visual acuity is satisfactory and the patient is coping well. ${ }^{14}$ The percentage of patients reporting difficulty in driving is nearly double in patients who underwent the procedure ( $28 \%$ for group B vs $14 \%$ for group C). Reading difficulty is the most common presenting complaint, although driving difficulty seems to play a bigger role when deciding to proceed with cataract surgery.

In our study $\mathrm{CI}$ and previous CVA were the only medical conditions that showed a significant difference in the group that did not go ahead with cataract surgery. Guidelines state that a stable period of 3 months is required before cataract surgery in case of recent myocardial infarction and this rule is often applied by many clinicians in situations of a recent CVA. ${ }^{6}$ Some studies have shown, that cataract surgery and subsequent improved vision can have a positive role in patients with CI. Cognitive testing is not routinely applied within the NHS in preoperative assessment. However, increasingly with an ageing population and more patients who present for cataract surgery, services may have to be planned in the future to take into account $\mathrm{CI}$ and how decisions are made for and with these patients. ${ }^{8}$ Interestingly over $45 \%$ of patients in both groups had systemic hypertension, but the difference between group $\mathrm{B}$ and $\mathrm{C}$ was not significant. Guidelines state that in case of poorly controlled blood pressure, cataract surgery should be deferred. Nonetheless, our findings suggest that this condition most likely did not affect the decision about cataract surgery. ${ }^{6}$

There was a higher number of ocular co-morbidities amongst the patients who did not have cataract surgery (Table 1). However, only age-related macular degeneration and other macular pathology (with exclusion of diabetic maculopathy), corneal pathology and amblyopia contributed to this statistically significant difference. These findings are similar to that found in the cataract national audit, where the above features were found to be adverse preoperative risk factors for good visual outcome. ${ }^{15,16}$ The most recent audit on modern cataract surgery was performed at an Australian urban teaching hospital and included data from 3,740 eyes in years 2006-2013. ${ }^{17}$ The results of preoperative ocular co-pathology are comparable to our study with about $70 \%$ patients not having any ocular pathology. Age-related macular degeneration (8.4\%) and glaucoma (8.56\%) are the highest recorded eye conditions. ${ }^{17}$ Some studies have shown possible 
association between having cataract surgery and increased risk of age-related macular degeneration progression. ${ }^{18}$ This perhaps goes someway in explaining why these patients did not have surgery.

Surprisingly social circumstances (such as living alone) showed no differences between the groups and is perhaps a reflection of the increasing numbers of elderly living alone.

The practice for listing for cataract surgery shows wide variation in Scotland. There are no specific guidelines for visual acuity threshold for referral from primary to secondary care or deciding on surgery. Specific guidance for the Scottish population from Health Technology sources recommends that the overriding decision should be based on individual patient visual disability and informed decision between consultant and patient. ${ }^{19,20}$ This approach naturally leads to more referrals than would be expected, if there were more categorical visual acuity guidance. In Scotland amongst the 14 health board services there is variation from direct listing from community optometry to surgical lists to patients being seen between one to three times in hospital before cataract surgery.

There are some limitations to our study. The decision to not go ahead with cataract surgery takes multiple factors into account and is also sensitively dependent on both clinician and patient coming to individual decision making which is not always consistent practice. It has been suggested previously that patient preparation, education, and emotional status are significant factors prior to cataract surgery. ${ }^{21}$ Thus, while we are able to describe the characteristics of this large series of two groups in detail, we accept that the decision to treat cannot be simply attributed to single factors. A small number of second eye cataract surgeries (approximately $10 \%$ from previous audits) are directly listed after first eye surgery, thus omitting OSCC assessment. Patients are also directly listed from glaucoma, diabetic, and uveitis services for cataract surgery. These represent the slightly more complex cases with poorly dilating pupils, posterior synechia, post-trabeculectomy, and narrow angle cases.

In connection with the Fife unit, our study has led us to believe that we need to place more effort and targeted resource into the interface between primary and secondary care. The current practice is that we have given the Fife optometrist generic guidance on the points that should be covered in discussion with patients and supplying a patient information leaflet before referral to the Hospital Eye Service (HES). In future we are considering a more specific questionnaire that would require completion before referral. A second step would be to offer a telephone service to patients with good vision (6/12 and better) discussing in detail the degree of visual disability before hospital appointment. These steps may give the patient more time to understand and digest all information before making the ultimate decision to consent to cataract surgery. Finally, those with a past attendance to our department may benefit from a clinician reviewing and summarizing their notes, and sharing past ocular history with the optometry department before further hospital appointments. Avoiding false positive referrals to the HES stands to save significant resources that can be diverted to other aspects of the ophthalmic service.

With regards to ophthalmic training, studies (including cataract national audit) have shown that the biggest risk to outcome of cataract surgery is the procedure being performed by a trainee doctor. ${ }^{15}$ Some units have moved towards training and non-training lists. ${ }^{11,22,23}$ This has its own challenges in terms of how patients give consent. In terms of risk factors for cataract surgery (eg, very old age, myopia, advanced hypermetropia, deep brow, pseudoexfoliation, etc) very few patients presented with these features (range of $0.2 \%-1.5 \%$ ). The preference in our unit is to have consistently mixed lists where every list has a trainee of varied experience. Our study shows that at most only about $10 \%$ of patients who underwent cataract surgery after attending the OSCC had ocular co-morbidity that could pose an additional technical challenge during the surgery. We also know that approximately $10 \%$ of our cataract surgery comes from lists at general and specialist clinics. Thus, a potential $80 \%$ of cases would be suitable for training and would not pose undue challenges for either trainee or supervising consultant. This supports our current arrangements and provision for training.

\section{Conclusion}

This study shows some very relevant findings in a large cohort of consecutive patients who presented to an OSCC unit in south-east Scotland in years 2008-2014. It is the first large audit to document modern phacoemulsification cataract surgery in a Scottish population in the last few years. Specially designed electronic patient records allow easy collection of a large quantity of data as part of routine clinical care and their undisputable value has been described previously. ${ }^{15}$ The data facilitate continuous refinement and appropriate allocation of resources for best patient outcomes.

Our unit in particular plans to redesign our primary and secondary care interface to reduce the cataract surgery false positive referral rate down to $10 \%$, from $20 \%$. We will continue to have mixed case lists for cataract surgery so that 
our trainees will have adequate and relevant cataract surgery experience for their level of training.

\section{Acknowledgments}

We would like to thank Dr Shona Sutherland and Dr Suzanne Brannan for the use of the CEPR on their patients.

\section{Disclosure}

The authors report no conflicts of interest in this work.

\section{References}

1. Erie JC. Rising cataract surgery rates: demand and supply. Ophthalmology. 2014;121(1):2-4.

2. Department of Health. National Eye Care Services Steering Group. First report of the National Eye Care Services Steering Group; 2004; gateway reference: 3170 . Available from: http://webarchive.nationalarchives. gov.uk/20130107105354/http://www.dh.gov.uk/prod_consum_dh/ groups/dh_digitalassets/@dh/@en/documents/digitalasset/dh_4080999. pdf. Accessed September 4, 2015.

3. Information Services Division: ISD Scotland [homepage on the Internet]. I1-I3 - Cataract patient journey: NHS Scotland, Waiting time for Outpatient Assessment, Waiting Time for Surgery (1st eye Cataract) and Waiting Time for Surgery (2nd Eye Cataract and One Stop Clinics), Ongoing waits for patients on waiting list. ISD; 2014. Available from http://www.isdscotland.org/Health-Topics/Waiting-Times/Publications/ data-tables.asp?id=699\#699. Accessed September 4, 2015.

4. Prokofyeva E, Wegener A, Zrenner E. Cataract prevalence and prevention in Europe: A literature review. Acta Ophthalmol. 2013;91(5):395-405.

5. Sparrow JM. Cataract surgical rates: is there overprovision in certain areas? Br J Ophthalmol. 2007;91(7):852-853

6. The Royal College of Ophthalmologists [homepage on the Internet]. Cataract Surgery Guidelines. The Royal College of Ophthalmologists Cataract Surgery Guidelines; 2010. Available from: https:// www.rcophth.ac.uk/wp-content/uploads/2014/12/2010-SCI-069Cataract-Surgery-Guidelines-2010-SEPTEMBER-2010.pdf. Accessed September 4, 2015.

7. Park JC, Ross AH, Tole DM, Sparrow JM, Penny J, Mundasad MV. Evaluation of a new cataract surgery referral pathway. Eye (Lond). 2009;23(2):309-313

8. Court H, McLean G, Guthrie B, Mercer SW, Smith DJ. Visual impairment is associated with physical and mental comorbidities in older adults: a cross-sectional study. BMC Med. 2014;12(1):181.

9. Keenan T, Rosen P, Yeates D, Goldacre M. Time trends and geographical variation in cataract surgery rates in England: study of surgical workload. Br J Ophthalmol. 2007;91(7):901-904.

10. Tey A, Grant B, Harbison D, Sutherland S, Kearns P, Sanders R. Redesign and modernisation of an NHS cataract service (Fife 1997-2004): multifaceted approach. BMJ. 2007;334(7585):148-152.

11. Rodrigues IA, Symes RJ, Turner S, Sinha A, Bowler G, Chan WH. Ophthalmic surgical training following modernising medical careers: regional variation in experience across the UK. BMJ Open. 2013;3(5). pii: e002578.

Clinical Ophthalmology

\section{Publish your work in this journal}

Clinical Ophthalmology is an international, peer-reviewed journal covering all subspecialties within ophthalmology. Key topics include: Optometry; Visual science; Pharmacology and drug therapy in eye diseases; Basic Sciences; Primary and Secondary eye care; Patient Safety and Quality of Care Improvements. This journal is indexed on Submit your manuscript here: http://www.dovepress.com/clinical-ophthalmology-journal
12. Edinburgh Evening News [homepage on the Internet]. Eye surgery outsource 'a waste' says college. Available from: http://www. edinburghnews.scotsman.com/news/eye-surgery-outsource-a-wastesays-college-1-3019711. Accessed September 4, 2015.

13. The Royal College of Ophthalmologists. Action on Cataracts. Good Practice Guidance. The Royal College of Ophthalmologists. Available from: https://www.rcophth.ac.uk/wp-content/uploads/2015/03/Actionon-cataracts-Jan-2000-dh_4014514.pdf. Accessed September 4, 2015.

14. Cao H, Zhang L, Li L, Lo S. Risk Factors for Acute Endophthalmitis following Cataract Surgery: A Systematic Review and Meta-Analysis. PLoS One. 2013;8(8):e71731.

15. Jaycock $\mathrm{P}$, Johnston RL, Taylor H, et al. The Cataract National Dataset electronic multi-centre audit of 55,567 operations: updating benchmark standards of care in the United Kingdom and internationally. Eye (Lond). 2009;23(1):38-49.

16. Sparrow JM, Taylor H, Qureshi K, et al. The Cataract National Dataset electronic multi-centre audit of 55,567 operations: risk indicators for monocular visual acuity outcomes. Eye (Lond). 2012;26(6):821-826.

17. Kahawita SK, Goggin M. Cataract surgery audit at an Australian urban teaching hospital. Clin Experiment Ophthalmol. 2015;43(6): 514-522.

18. Kessel L, Erngaard D, Flesner P, Andresen J, Tendal B, Hjortdal J. Cataract surgery and age-related macular degeneration. An evidencebased update. Acta Ophthalmol. Epub 2015 Jan 20.

19. Healthcare Improvement Scotland. What is the impact of using thresholds (both for referral and surgery) for first-eye cataract surgery on the delivery of the cataract service and the resources associated with it? 2012;(9). Available from: https://www.google.co.uk/url? sa $=\mathrm{t} \& \mathrm{rct}=\mathrm{j} \& \mathrm{q}=\& \mathrm{esrc}=\mathrm{s}$ $\&$ source $=$ web $\& c d=1 \& c a d=$ rja\&uact $=8 \& v e d=0 \mathrm{CDcQFjAAahUKEwjb}$ gYW5s-fHAhVBthoKHf6KB6s\&url=http $\% 3 \mathrm{~A} \% 2 \mathrm{~F} \% 2$ Fhealthcareimp rovementscotland.org\%2Fhis\%2Fidoc.ashx\%3Fdocid\%3D2852374234ec-486a-9cb4-6ef2566ffeb3\%26version\%3D-1\&usg=AFQjCNFCW epTjtd11E2Jy7IBR3sBWdfi2A\&sig2=jD22GK7nCgV1DaoZEFocjg\& bvm=bv.102022582,d.d2s. Accessed September 4, 2015.

20. Healthcare Improvement Scotland. Is it clinically and cost effective to perform second-eye cataract surgery in the absence of other ocular co-morbidities in patients who have already had first-eye surgery? 2012;(8). Available from: https://www.google.co.uk/url?sa=t\&rct=j\& $\mathrm{q}=\& \mathrm{esrc}=\mathrm{s} \&$ source $=$ web $\& \mathrm{~cd}=3 \& \mathrm{ved}=0 \mathrm{CCwQFjACahUKEwiWmN}$ fks-fHAhXDBBoKHaZ2Bxg\&url=http $\% 3 \mathrm{~A} \% 2 \mathrm{~F} \% 2$ Fhealthcareimpr ovementscotland.org\%2Fhis\%2Fidoc.ashx\%3Fdocid\%3D61b563c3c2f8-408f-8d34-6ec90be8e0a0\%26version\%3D-1\&usg=AFQjCNGP 3JlMemAwBLwIhEvmfiLFd1HtyQ\&sig2=7vDQ1ZFsYWW5q0rpH Q4Giw\&bvm=bv.102022582,d.d2s\&cad=rja. Accessed September 4, 2015.

21. Marback R, Temporini E, Kara Júnior N. Emotional factors prior to cataract surgery. Clinics (Sao Paulo). 2007;62(4):433-438.

22. Baxter JM, Lee R, Sharp JA, Foss AJ; Intensive Cataract Training Study Group. Intensive cataract training: a novel approach. Eye (Lond). 2013; 27(6):742-746.

23. Goh ES. Maximising safety of cataract surgery training: improving patient safety by reducing cataract surgery complication rates. Int $J$ Health Care Qual Assur. 2009;22(5):535-546.

PubMed Central and CAS, and is the official journal of The Society of Clinical Ophthalmology (SCO). The manuscript management system is completely online and includes a very quick and fair peer-review system, which is all easy to use. Visit http://www.dovepress.com/ testimonials.php to read real quotes from published authors. 